\title{
Predictive value of circulating NMR metabolic biomarkers for type 2 diabetes risk in the UK Biobank study
}

Fiona Bragg ${ }^{1,2^{*}}$, Eirini Trichia ${ }^{1,2^{*}}$, Diego Aguilar-Ramirez ${ }^{2}$, Jelena Bešević ${ }^{2}$, Sarah Lewington ${ }^{1,2,3}$, Jonathan Emberson ${ }^{1,2}$

1. MRC Population Health Research Unit, Nuffield Department of Population Health, University of Oxford

2. Clinical Trial Service Unit \& Epidemiological Studies Unit, Nuffield Department of Population Health, University of Oxford

3. UKM Medical Molecular Biology Institute (UMBI), Universiti Kebangsaan Malaysia, Kuala Lumpur, Malaysia

${ }^{\star}$ Equal contribution

\author{
Address for correspondence: \\ Dr Fiona Bragg \\ Nuffield Department of Population Health \\ University of Oxford \\ Old Road Campus \\ OX3 7LF, UK \\ Tel: 44-1865-743947 \\ fiona.bragg@ndph.ox.ac.uk
}

11 October 2021 
medRxiv preprint doi: https://doi.org/10.1101/2021.10.11.21264833; this version posted October 14, 2021. The copyright holder for this preprint (which was not certified by peer review) is the author/funder, who has granted medRxiv a license to display the preprint in

\section{Summary}

Background: Effective targeted prevention of type 2 diabetes (T2D) depends on accurate prediction of disease risk. We assessed the role of metabolomic profiling in improving T2D risk prediction beyond conventional risk factors.

Methods: NMR-metabolomic profiling was undertaken on baseline plasma samples in 65,684 UK Biobank participants without diabetes and not taking lipid-lowering medication. Cox regression yielded adjusted hazard ratios for the associations of 143 individual metabolic biomarkers (including lipids, lipoproteins, fatty acids, amino acids, ketone bodies and other low molecular weight metabolic biomarkers) and 11 metabolic biomarker principal components (PCs) (accounting for $90 \%$ of total variance in individual biomarkers) with incident T2D. These 11 PCs were added to established models for T2D risk prediction, and measures of risk discrimination (cstatistic) and reclassification (continuous net reclassification improvement [NRI], integrated discrimination index [IDI]) were assessed.

Findings: During median 11.9 (IQR 11.1-12.6) years' follow-up, 1719 participants developed T2D. After accounting for multiple testing, 118 metabolic biomarkers showed independent associations with T2D risk (false discovery rate controlled $p<0.05)$, of which 103 persisted after additional adjustment for HbA1c. Overall, 10 metabolic biomarker PCs were independently associated with T2D. Addition of PCs to the established risk prediction model (including age, sex, parental history of diabetes, body mass index and $\mathrm{HbA} 1 \mathrm{C}$ ) improved T2D risk prediction as assessed by the c-statistic (increased from 0.802 [95\% $\mathrm{Cl} 0.791-0.812$ ] to 0.830 [0.822-0.841]), continuous NRI (0.44 [0.38-0.49]), and relative (15.0\% [10.5\%-20.4\%]) and absolute $(1.5[1.0-1.9])$ IDI.

Interpretation: When added to conventional risk factors, circulating NMR-based metabolic biomarkers enhanced T2D risk prediction.

Funding: BHF, MRC, CRUK 
medRxiv preprint doi: https://doi.org/10.1101/2021.10.11.21264833; this version posted October $14,2021$. The copyright holder for this preprint (which was not certified by peer review) is the author/funder, who has granted medRxiv a license to display the preprint in

\section{Introduction}

Both population-level and individual high-risk prevention approaches are essential for addressing the major and rising global public health challenge of type 2 diabetes (T2D). Fundamental to the latter is the ability to accurately predict future T2D risk, enabling targeted or precision prevention of the disease,${ }^{1}$ and ultimately of its complications. $^{2}$ Existing risk prediction models are imperfect, frequently overestimating T2D risk ${ }^{3}$ and often lacking sufficient specificity to be of use clinically. ${ }^{4}$ Moreover, they characteristically rely on distal risk factors, and consider, at best, only limited molecular pathways. This contrasts with the classical T2D prodrome, comprising dysregulation of multiple molecular pathways over a period of many years. $^{5}$

Through metabolomic profiling, large numbers of biomarkers across multiple biological pathways_-proximal and distal—can be quantified in a single measurement, capturing the consequences of genetic variation, environmental influences, and their interactions. Prospective studies have established associations of diverse circulating metabolic biomarkers (e.g., amino acids, fatty acids, hexoses, lipids) with T2D. ${ }^{6}$ As well as providing aetiological insights, these data might feasibly contribute valuable risk prediction information. Previous studies investigating the ability of metabolomics to improve T2D risk prediction over established risk factors have, with the exception of a small number of studies, ${ }^{7,8}$ based their findings on limited T2D cases, ${ }^{9-14}$ frequently investigating only small numbers or single subclasses of metabolic biomarkers, ${ }^{8-13}$ or have used untargeted metabolomic profiling, including unknown biomarkers ${ }^{13,14}$ with limited translational potential. The 
medRxiv preprint doi: https://doi.org/10.1101/2021.10.11.21264833; this version posted October $14,2021$. The copyright holder for this preprint (which was not certified by peer review) is the author/funder, who has granted medRxiv a license to display the preprint in

All rights reserved. No reuse allowed without permission.

resulting inconsistent findings leave on-going uncertainty regarding the value of metabolomic profiling for T2D risk prediction.

Using recently-available data from the UK Biobank study, we characterise the prospective associations of circulating metabolic biomarkers, quantified using a highthroughput targeted NMR metabolomics platform, with risk of incident T2D, and examine whether addition of these biomarkers to established models improves prediction of T2D risk. 
medRxiv preprint doi: https://doi.org/10.1101/2021.10.11.21264833; this version posted October $14,2021$. The copyright holder for this preprint (which was not certified by peer review) is the author/funder, who has granted medRxiv a license to display the preprint in

\section{Methods}

\section{Study population}

Details of the UK Biobank (UKB) study design and population have been described previously.$^{15}$ Briefly, postal invitations to participate were sent to 9.2 million adults aged 40-69 years, living in England, Wales or Scotland and registered with the UK National Health Service. A response rate of 5.5\% was achieved, and 502,493 participants were enrolled.

\section{Data collection}

The baseline survey took place between 2006 and 2010 in 22 assessment centres. Self-administered touchscreen questionnaires collected information on sociodemographic and lifestyle factors (including diet, physical activity, smoking and alcohol drinking), and personal (supplemented by verbal interview) and family medical history. Physical measurements, including blood pressure, height, weight, waist circumference (WC) and hip circumference, were undertaken using calibrated instruments with standard protocols. A non-fasting venous blood sample was collected, with the time since last food or drink recorded. After minimal processing at assessment centres, samples were shipped to a central facility for processing and long-term storage at $-80^{\circ} \mathrm{C}$. Biochemical biomarkers were measured on stored baseline samples at a central UK Biobank laboratory between 2014 and $2017 .{ }^{16}$ These included HDL-cholesterol and triglycerides (AU5400; Beckman Coulter) and HbA1c (VARIANT II TURBO Hemoglobin Testing System; Bio-Rad). Repeat surveys collected the same information as at baseline in addition to certain enhancements; 
medRxiv preprint doi: https://doi.org/10.1101/2021.10.11.21264833; this version posted October 14, 2021. The copyright holder for this preprint (which was not certified by peer review) is the author/funder, who has granted medRxiv a license to display the preprint in

All rights reserved. No reuse allowed without permission.

they comprised a resurvey of $\sim 20,000$ participants in $2012-13$, and an on-going survey of $\sim 100,000$ participants which commenced in $2014 . .^{17,18}$

All participants consented to be followed-up through linkage to health-related records. These included prior and prospective data on dates and causes of hospital admissions (Hospital Episode Statistics in England, Patient Episode Database for Wales, and Scottish Morbidity Record), and primary care clinical events and prescribing (available for $\sim 45 \%$ of participants), as well as date and cause of death obtained from national death registries.

Ethics approval for the UK Biobank was obtained from the North West Multi-centre Research Ethics Committee (Ref: 11/NW/0382). All participants provided informed written consent.

\section{Metabolic biomarker quantification}

A high-throughput NMR-metabolomics platform ${ }^{19,20}$ was used to undertake metabolomic profiling in baseline plasma samples from a randomly-selected subset of $\sim 120,000$ UKB participants. ${ }^{21}$ This simultaneously quantified 249 metabolic biomarkers (168 directly-measured and 81 ratios of these), including lipids, fatty acids, amino acids, ketone bodies and other low molecular weight metabolic biomarkers (e.g., gluconeogenesis related metabolites), as well as lipoprotein subclass distribution, particle size and composition. A subset of 143 (Webtable 1) were selected for inclusion in the presented analyses, focussing on those which were directly measured and could not be inferred from other biomarkers. 
medRxiv preprint doi: https://doi.org/10.1101/2021.10.11.21264833; this version posted October $14,2021$. The copyright holder for this
preprint (which was not certified by peer review) is the author/funder, who has granted medRxiv a license to display the preprint in All rights reserved. No reuse allowed without permission.

\section{Assessment of incident type 2 diabetes status}

Incident T2D status was ascertained through: i) self-report of T2D diagnosis or glucose-lowering medication use at repeat surveys; ii) coded T2D diagnoses recorded in primary care, hospital admission or death registry data; or iii) glucoselowering medication prescribing in primary care data (Webtable 2). Only those participants without diagnostic codes for other specified diabetes types (type 1/ malnutrition-related/ other specified diabetes) were considered to have T2D.

\section{Statistical analysis}

Analyses excluded those with previously-diagnosed diabetes of any type (based on self-report, primary care or inpatient hospital data), taking regular glucose-lowering medication (based on self-report or primary care data) or with $\mathrm{HbA} 1 \mathrm{c} \geq 6.5 \%$ (corresponding to $48 \mathrm{mmol} / \mathrm{mol}$ and consistent with undiagnosed diabetes) at the baseline survey. Those with missing or extreme NMR-biomarker or covariate data (see below), or who were taking lipid-lowering medications at recruitment, were also excluded from the main analyses (Webfigure 1).

All NMR-biomarkers were log transformed and standardised. Principal component analysis was then employed to reduce the large number of correlated NMR-

biomarkers (Webfigure 2) to a much smaller number of uncorrelated principal components (PCs) which retained most $(>90 \%)$ of the variance in the individual biomarkers. Cox regression was used to assess the individual relevance of each NMR-biomarker (and each PC) to risk of incident T2D. First, to examine the shape of the associations, participants were grouped into baseline categories defined by quartiles of their distributions. Subsequently, continuous analyses of each NMRbiomarker (and each PC) were done to estimate the HR per 1-SD higher baseline 
medRxiv preprint doi: https://doi.org/10.1101/2021.10.11.21264833; this version posted October 14, 2021. The copyright holder for this preprint (which was not certified by peer review) is the author/funder, who has granted medRxiv a license to display the preprint in All rights reserved. No reuse allowed without permission.

level. Cox models were stratified by age-at-risk (5-year age groups) and sex, and adjusted for assessment centre (22 centres), Townsend deprivation index (numeric), smoking (4 categories), alcohol drinking (4 categories), body mass index (BMI) (numeric), waist-to-hip ratio (WHR) (numeric), fasting time (numeric) and spectrometer (6 spectrometers). Participants who did not develop incident T2D were censored at the earliest of death, loss to follow-up or 31 December 2020. For significance testing, the Benjamini-Hochberg method was used to control the false discovery rate (FDR). ${ }^{22}$ Sensitivity analyses examined associations separately by age ( $<55$ vs $\geq 55$ years) and sex, and after additional adjustment for other factors (HbA1c, ethnicity, parental history of diabetes, physical activity and dietary factors [whole and refined grains, fruit, vegetables, cheese, unprocessed red meat, processed meat, non-oily and oily fish, type of spread, caffeinated and decaffeinated coffee, tea and dietary supplements]). In addition, the impact of excluding the first three years of follow-up was assessed, and, for the analysis of each PC, mutual adjustment for all preceding PCs.

Then, to assess whether circulating NMR-biomarkers could improve prediction of T2D risk, the selected PCs were added to 'traditional' T2D risk prediction models. ${ }^{23}$ Two such models were assessed: a 'basic' model, including age $(<50,50-64, \geq 65$ years), sex, parental history of diabetes, BMI $\left(<25.0,25.0-29.9, \geq 30.0 \mathrm{~kg} / \mathrm{m}^{2}\right)$ and HbA1c (<6.0\% vs $\geq 6.0 \%)$; and an 'extended' model, which additionally included blood pressure $(\leq 130 / 85 \mathrm{mmHg}$ and not taking anti-hypertensive medication vs $>130 / 85 \mathrm{mmHg}$ or taking anti-hypertensive medication), HDL-cholesterol (<1.0 vs $\geq 1.0 \mathrm{mmol} / \mathrm{L}$ in $\mathrm{men} ;<1.3 \mathrm{vs} \geq 1.3 \mathrm{mmol} / \mathrm{L}$ in women), triglycerides ( $<1.7 \mathrm{vs} \geq 1.7$ $\mathrm{mmol} / \mathrm{L})$, and $\mathrm{WC}\left(\leq 102 \mathrm{vs}>102 \mathrm{~cm}\right.$ in men; $\leq 88 \mathrm{vs}>88 \mathrm{~cm}$ in women). ${ }^{23}$ The discriminatory ability of each model before and after including the PCs was assessed 
medRxiv preprint doi: https://doi.org/10.1101/2021.10.11.21264833; this version posted October 14, 2021. The copyright holder for this preprint (which was not certified by peer review) is the author/funder, who has granted medRxiv a license to display the preprint in

All rights reserved. No reuse allowed without permission.

using Harrell's c-statistic, ${ }^{24}$ and the likelihood ratio test was used to compare the fits of nested models (i.e., those including versus excluding the PCs). Relative and absolute integrated discrimination improvement (IDI) ${ }^{25}$ and continuous net reclassification improvement $(\mathrm{NRI})^{26}$ were estimated to assess risk reclassification. To avoid model optimism, bootstrapping was used to create bias-corrected estimates and Cls for the c-statistics, IDI and NRI. To test model calibration, observed T2D event rates for absolute predicted risk deciles were plotted against their predicted event rates, and calibration slopes were estimated using a Cox regression analysis of predicted risk on observed risk. Calibration slopes and their confidence intervals were estimated from 10-fold cross-validation (pooled using inverse variance weighting). Subsequent analyses assessed the performance of the four risk prediction models solely among 13,695 participants taking lipid-lowering medications at baseline.

Analyses were conducted using SAS (version 9.4) and R (version 3.6.2).

Role of funding sources

Funders had no role in study design, data collection, analysis, interpretation, or report writing. All authors had full access to the data and analyses, and share final responsibility for the decision to submit for publication. 
medRxiv preprint doi: https://doi.org/10.1101/2021.10.11.21264833; this version posted October $14,2021$. The copyright holder for this preprint (which was not certified by peer review) is the author/funder, who has granted medRxiv a license to display the preprint in All rights reserved. No reuse allowed without permission.

\section{Results}

Of the original 502,493 UKB participants, a random subset of 118,036 (23\%) had NMR-biomarker data (Webfigure 1, Webtable 3). Of these, 65,684 (56\%) had no prior diabetes, were not taking lipid-lowering medication and had complete NMRbiomarker (and other) data, and were included in subsequent analyses. The mean (SD) age was $55.2(8.0)$ years, and $58 \%(n=37,849)$ were women (Table 1). During 0.8 million person-years of follow-up (median 11.9 [IQR 11.1-12.6]), 1719 cases of incident T2D were identified. Participants who developed T2D were more likely to be male and, at the time of recruitment, tended to be older and of lower socioeconomic status than those who did not develop T2D. They also had higher levels of adiposity, were more likely to be current regular smokers, but less likely to be current regular alcohol drinkers, and more frequently had a parental history of diabetes.

After adjustment for potential confounding factors and accounting for multiple testing, 118 of the 143 metabolic biomarkers showed statistically significant associations with risk of incident T2D (FDR controlled $p<0.05$ ) (Figure 1, Webtable 1, Webfigure 3). Among the strongest positive associations were those of VLDL particle concentrations, particularly larger VLDL particles, and the lipid concentrations within them. Triglyceride concentrations in all 14 lipoprotein subclasses were also very strongly positively associated with incident T2D. Conversely, concentrations of larger HDL particles, and the cholesterol and phospholipids within those particles, were inversely associated with T2D. Higher branched chain amino acid (BCAA)-leucine, isoleucine and valine-concentrations were associated with higher risk of T2D, as were higher concentrations of alanine, phenylalanine and tyrosine. Glutamine and glycine were inversely associated with T2D. Relative to total fatty acids, higher 
medRxiv preprint doi: https://doi.org/10.1101/2021.10.11.21264833; this version posted October $14,2021$. The copyright holder for this preprint (which was not certified by peer review) is the author/funder, who has granted medRxiv a license to display the preprint in All rights reserved. No reuse allowed without permission.

concentrations of polyunsaturated, omega- 3 and omega- 6 fatty acids, and of docosahexaenoic and linoleic acids were associated with lower T2D risk, whereas higher concentrations of saturated and monounsaturated fatty acids were associated with higher T2D risk. Higher plasma glycoprotein acetyls, a marker of inflammation, were also associated with higher T2D risk.

After additional adjustment for $\mathrm{HbA} 1 \mathrm{c}$, many associations were moderately attenuated but statistically significant associations of most biomarkers $(n=103)$ with T2D remained (Webtable 1). Further adjustment for ethnicity, parental history of diabetes, physical activity and dietary factors did not materially alter the associations. There were no marked differences in the relationships between men and women (Webfigure 4), by age at baseline (Webfigure 5), or after exclusion of the first three years of follow-up (Webfigure 6).

The first 11 PCs of the NMR-biomarkers explained $90 \%$ of the total variance present in the 143 individual biomarkers (Webfigure 7). The PC loadings from these 11 PCs are shown in Webfigure 8 (the larger a biomarker's loading, positive or negative, the more it contributes to that PC) and the associations of these PCs with incident T2D are shown in Webtable 4. The major contributors to PC1 were the VLDL and LDL particle concentrations and the lipid concentrations within those particles, while for PC2 they included large HDL particles and lipid concentrations within them. PC1 and PC2 showed opposing associations with T2D (adjusted HR 1.23 [95\% Cl 1.17-1.30] and 0.78 [0.73-0.82], respectively). Biomarkers across multiple molecular pathways, including lipid concentrations in LDL and HDL particles and apolipoprotein concentrations, were prominent contributors to PC3 (HR 1.23 [95\% Cl 1.18-1.29]). Within PC4 (HR 1.09 [95\% Cl 1.04-1.15]), loadings were high for small and very 
medRxiv preprint doi: https://doi.org/10.1101/2021.10.11.21264833; this version posted October $14,2021$. The copyright holder for this preprint (which was not certified by peer review) is the author/funder, who has granted medRxiv a license to display the preprint in All rights reserved. No reuse allowed without permission.

large HDL particles and their lipid concentrations, and amino acids were the major contributors to PC5 (1.07 [1.02-1.13]). Fatty acids were dominant in PC6 (0.97 [95\% $\mathrm{Cl} 0.92-1.01])$ and also PC7 (0.74 [0.70-0.78]), in which ketone bodies also had large factor loadings. Overall, 10 of the 11 PCs were independently associated with incident T2D, and largely remained so after sequential adjustment for preceding PCs (Webtable 4).

In the two traditional risk prediction models, all risk factors were strongly and independently associated with T2D risk (Webtable 5). Older age, male sex, parental history of diabetes, higher levels of adiposity, blood pressure, $\mathrm{HbA} 1 \mathrm{c}$ and triglycerides, and lower HDL-cholesterol concentration were all associated with higher risk. These relationships largely persisted, although with modest attenuation of some, when metabolic biomarker PCs were added. For both models, 8 of the 11 PCs were significantly associated with T2D risk independently of all other risk factors.

The basic T2D risk prediction model (incorporating age, sex, parental history of diabetes, BMI and $\mathrm{HbA1c}$ ) demonstrated good calibration of observed versus predicted T2D rates across deciles of predicted risk (calibration slope: 0.99 [95\% Cl 0.95-1.02]) (Figure 2). This did not meaningfully change after addition of metabolic biomarker PCs $(0.98$ [95\% Cl 0.95-1.02]). Table 2 summarises measures of model fit and performance. Addition of the PCs to the basic model resulted in a $17 \%$ increase in the chi-square statistic, and yielded an increase in the c-statistic from $0.802(95 \% \mathrm{Cl} 0.791-0.812)$ to $0.830(0.822-0.841)$. Improved T2D risk prediction on addition of the PCs was also evidenced by estimates of the overall continuous NRI $(0.44[95 \% \mathrm{Cl} 0.38-0.49])$, with an improvement of $0.15(0.12-0.20)$ in events and 
medRxiv preprint doi: https://doi.org/10.1101/2021.10.11.21264833; this version posted October 14, 2021. The copyright holder for this preprint (which was not certified by peer review) is the author/funder, who has granted medRxiv a license to display the preprint in All rights reserved. No reuse allowed without permission.

$0.28(0.26-0.31)$ in non-events, and both absolute $(1.5[1.0-1.9])$ and relative $(15.0 \%$ [10.5\%-20.4\%]) IDI. The extended model (basic model plus blood pressure, WC, HDL-cholesterol and triglycerides) achieved a c-statistic of 0.829 (95\% Cl 0.8190.838). Modest improvements in model fit and performance were observed following addition of metabolic biomarker PCs to this model, with a $6 \%$ increase in the chisquare statistic, a c-statistic of 0.837 (95\% Cl $0.831-0.848)$, an overall continuous $\mathrm{NRI}$ of $0.22(0.17-0.28)$, an absolute IDI of $0.7(0.4-1.1)$ and a relative IDI of $6.3 \%$ (4.1\%-9.8\%). The extended model was well-calibrated, both with and without inclusion of metabolic biomarker PCs $(0.99$ [95\% Cl 0.96-1.02] and 0.98 [0.95-1.01], respectively). When analyses were repeated among participants taking lipid-lowering medications at baseline, c-statistics for the four individual T2D risk prediction models were lower than in the main study population, but estimates of relative performance of the nested models were broadly comparable (Webtable 6). 
medRxiv preprint doi: https://doi.org/10.1101/2021.10.11.21264833; this version posted October $14,2021$. The copyright holder for this
preprint (which was not certified by peer review) is the author/funder, who has granted medRxiv a license to display the preprint in

\section{Discussion}

This prospective population-based cohort study of over 65,000 middle-aged adults with 1719 cases of new-onset T2D is, to our knowledge, the largest study to-date to examine the predictive value of circulating metabolic biomarkers for T2D risk. Strong independent associations of diverse biomarkers, quantified using targeted NMRbased metabolomic profiling, including lipoprotein particle size and composition, amino acids and fatty acids, with risk of incident T2D were observed. When added to an established risk prediction model comprising basic clinical risk factors and $\mathrm{HbA1c}$, PCs derived from 143 circulating biomarkers substantially improved T2D risk prediction.

Our study found strong positive associations of VLDL particle measures and triglyceride concentrations with incident T2D risk, and inverse associations of HDL particle size and lipids within larger HDL particles. These findings are qualitatively, and broadly quantitatively, consistent with previous studies, ${ }^{27,28}$ and are characteristic of lipoprotein profiles associated with insulin resistance ${ }^{29}$ This is also thought to underlie the strong positive associations of BCAAs-leucine, isoleucine and valine - with risk of T2D observed in UKB and in previous studies among diverse populations. ${ }^{6,8,27}$ More specifically, genetic association studies have shown increased BCAA levels as a consequence of insulin resistance, ${ }^{30}$ which, in turn, appear to be causally related to T2D. ${ }^{31}$ We replicated findings of studies showing higher levels of phenylalanine, tyrosine and alanine, $, 6,8,27$ and lower concentrations of glutamate ${ }^{6,27}$ and glycine ${ }^{6}$ several years prior to T2D diagnosis, and the observed T2D-associated fatty acid profiles are broadly consistent with previous investigations. ${ }^{27,32}$ Insulin resistance and inflammation are postulated to underlie 

medRxiv preprint doi: https://doi.org/10.1101/2021.10.11.21264833; this version posted October $14,2021$. The copyright holder for this
preprint (which was not certified by peer review) is the author/funder, who has granted medRxiv a license to display the preprint in All rights reserved. No reuse allowed without permission.

some or all of these associations, ${ }^{6,8,32}$ but the nature of the relationships of these and other metabolic biomarkers with T2D, including their causal significance, remains uncertain. Despite this, these findings provide clear evidence of the relevance of diverse metabolic biomarkers to T2D risk.

The basic T2D risk prediction model examined in the present study, which included standard clinical risk predictors and $\mathrm{HbA} 1 \mathrm{c}$, demonstrated good discriminatory ability in the UKB population, yielding a c-statistic (0.80) consistent with that reported for similar models across varied populations. ${ }^{33}$ This highlights one of the major challenges of identifying novel predictive biomarkers for T2D. That is, that established clinical risk factors perform so well in predicting T2D risk that achieving clinically meaningful improvements above and beyond these is difficult. Despite this, addition of metabolic biomarkers to this model improved, albeit modestly, model fit and risk discrimination (c-statistic 0.83). Although some previous studies have observed no improvement in risk discrimination with addition of metabolic biomarkers to similar traditional risk prediction models, ${ }^{9,12,34}$ several have investigated the impact of only limited biomarkers. ${ }^{9,12}$ Inclusion of more diverse biomarkers has tended to achieve greater gains in model discrimination. ${ }^{7,14,27}$ For example, in a case-cohort study in Germany, comprising 800 T2D cases and a randomly-selected subcohort of 2282 adults (mean follow-up 7 years), addition of 14 metabolic biomarkers (including hexoses, amino acids and fatty acids) to an established T2D risk score, comprising clinical risk factors and glycaemia, resulted in moderate, but statistically significant, improvement in risk discrimination (increase in c-statistic from 0.901 to 0.912 ; $p<0.0001) .{ }^{7}$ However, even these studies have tended to investigate highly selected subsets of biomarkers. In contrast, use of principal component analysis in the present study facilitated inclusion of information from all 143 metabolic biomarkers, 
medRxiv preprint doi: https://doi.org/10.1101/2021.10.11.21264833; this version posted October $14,2021$. The copyright holder for this preprint (which was not certified by peer review) is the author/funder, who has granted medRxiv a license to display the preprint in

All rights reserved. No reuse allowed without permission.

despite their highly correlated nature. Many individual biomarkers most strongly associated with T2D were prominent contributors to the PCs selected for inclusion in risk prediction models, most of which were associated with incident T2D in fully adjusted regression models.

The only modest, and non-significant, gains in discrimination when metabolic biomarkers were added to the extended T2D risk prediction model in the present study likely reflects overlap between measured metabolic biomarkers and bloodbased risk factors included in the extended model, limiting the clinical relevance of this comparison given both assay types would unlikely be used simultaneously. However, it may also reflect the insensitivity of the c-statistic to improvements in predictive performance with addition of new, even strong, risk predictors to established models. ${ }^{35}$ More global measures of model performance provided strong supportive evidence of the value of metabolic biomarkers for T2D risk prediction. Their addition to the basic risk prediction model was associated with improvement in the prediction of T2D using measures of risk reclassification, specifically the IDI and continuous NRI. Of note, the NRI was driven more by reductions in predicted risk among participants who did not develop T2D, suggesting metabolomic profiling may be particularly valuable for reducing unnecessary prevention interventions among individuals at low risk of T2D. Increasing availability of standardised, quantitative, high-throughput metabolomics platforms, such as that used in the current study, underscores the translational potential of these findings. Moreover, the metabolomic profiling data these provide may be of wider clinical relevance (e.g., for diagnosis and risk assessment of other cardiometabolic diseases). ${ }^{20}$ 

medRxiv preprint doi: https://doi.org/10.1101/2021.10.11.21264833; this version posted October $14,2021$. The copyright holder for this
preprint (which was not certified by peer review) is the author/funder, who has granted medRxiv a license to display the preprint in All rights reserved. No reuse allowed without permission.

In addition to the large number of incident T2D events, our study has several strengths. An established targeted NMR-metabolomics platform, with existing clinical regulatory approvals, ${ }^{21}$ was used; as well as enabling quantification of diverse biomarkers, this facilitates comparisons between study populations and enhances the potential clinical relevance. Moreover, high levels of correlation between NMR and standard clinical chemistry derived concentrations of a subset of biomarkers (Webfigure 9) supports the validity of the approach. ${ }^{36}$ Exclusion of participants taking lipid-lowering medication avoided treatment-associated biases, although the broadly comparable performance of the nested risk prediction models in this subpopulation (with a higher frequency of incident T2D) demonstrates the wider generalisability of our findings. Finally, the cohort study design avoided potential biases and loss of precision which may affect more frequently-used nested casecontrol and case-cohort designs. However, the study also has limitations. Incident T2D was limited to diagnosed cases; although resulting misclassification would likely underestimate associations of metabolic biomarkers with T2D, the relative improvements in model performance (between models with versus without metabolic biomarkers) should be largely unaffected by misclassification in outcome assessment. Quantification of metabolic biomarkers in non-fasting blood samples may have increased inter- and intra-individual variation in biomarker concentrations, and the lack of repeat measurements prevented assessment of, and adjustment for, the latter. However, the main analyses adjusted for fasting time, which accounts for only a small proportion of variation in plasma metabolic biomarker concentrations, ${ }^{37}$ and biomarker measurements at a single point in time are more relevant in the context of risk prediction. Finally, independent validation of the risk prediction findings was not performed, and, given the lifestyle, and health-related 
medRxiv preprint doi: https://doi.org/10.1101/2021.10.11.21264833; this version posted October 14, 2021. The copyright holder for this preprint (which was not certified by peer review) is the author/funder, who has granted medRxiv a license to display the preprint in

All rights reserved. No reuse allowed without permission.

characteristics of the UKB population, ${ }^{38}$ the results may not necessarily be generalisable to other populations at higher risk of future T2D.

In summary, this study provides large-scale evidence of the incremental predictive value of metabolomic profiling for prediction of T2D risk. Addition of data on 143 circulating metabolic biomarkers, with replicated prospective associations with T2D, to an established risk prediction model comprising basic clinical risk factors and $\mathrm{HbA1c}$ improved T2D risk discrimination and classification. This serves to illustrate the utility of large-scale biobanks for assessment of the clinical relevance and value of emerging biomarkers. Moreover, given increasing availability, including in clinical settings, of high-throughput, comprehensive, targeted metabolomic profiling, these findings have translational potential for enhanced T2D risk stratification and precision prevention. 
medRxiv preprint doi: https://doi.org/10.1101/2021.10.11.21264833; this version posted October 14, 2021. The copyright holder for this preprint (which was not certified by peer review) is the author/funder, who has granted medRxiv a license to display the preprint in

All rights reserved. No reuse allowed without permission.

Acknowledgements: This research used the UK Biobank resource (application number 30418). We thank the participants of UK Biobank for their contribution to the resource. The authors are grateful to Nightingale Health Ltd. for providing early access to UK Biobank NMR metabolomics data during Nightingale Health's exclusivity period, prior to the resource being made openly available to the scientific community.

Author contributions: All authors were involved in study design, analysis of data, interpretation, or writing the report.

Data sharing: The underlying data are open access through application to the UK Biobank, and materials and methods will be made freely available through the UK Biobank as part of this project.

Funding: The British Heart Foundation, Medical Research Council and Cancer Research UK provide core funding to the Oxford CTSU. DAR acknowledges support from the BHF Centre of Research Excellence, Oxford (Grant code RE/13/1/30181). $S L$ reports grants from the Medical Research Council (MRC) and research funding from the US Centers for Disease Control and Prevention Foundation (with support from Amgen) during the conduct of the study. JE reports grants from Boehringer Ingleheim, Regeneron and Astra Zeneca outside the submitted work. 
medRxiv preprint doi: https://doi.org/10.1101/2021.10.11.21264833; this version posted October 14, 2021. The copyright holder for this preprint (which was not certified by peer review) is the author/funder, who has granted medRxiv a license to display the preprint in

\section{References}

1. Gillies CL, Abrams KR, Lambert PC, et al. Pharmacological and lifestyle interventions to prevent or delay type 2 diabetes in people with impaired glucose tolerance: systematic review and meta-analysis. BMJ 2007; 334(7588): 299.

2. Gong Q, Zhang P, Wang J, et al. Morbidity and mortality after lifestyle intervention for people with impaired glucose tolerance: 30 -year results of the Da Qing Diabetes Prevention Outcome Study. Lancet Diabetes Endocrinol 2019; 7(6): 452-61.

3. Abbasi A, Peelen LM, Corpeleijn E, et al. Prediction models for risk of developing type 2 diabetes: systematic literature search and independent external validation study. BMJ 2012; 345: e5900.

4. Noble D, Mathur R, Dent T, Meads C, Greenhalgh T. Risk models and scores for type 2 diabetes: systematic review. BMJ 2011; 343: d7163.

5. Færch K, Witte DR, Tabák AG, et al. Trajectories of cardiometabolic risk factors before diagnosis of three subtypes of type 2 diabetes: a post-hoc analysis of the longitudinal Whitehall II cohort study. Lancet Diabetes Endocrinol 2013; 1(1): 43-51.

6. Guasch-Ferré M, Hruby A, Toledo E, et al. Metabolomics in Prediabetes and Diabetes: A Systematic Review and Meta-analysis. Diabetes Care 2016; 39(5): 833-46.

7. Floegel A, Stefan N, Yu Z, et al. Identification of serum metabolites associated with risk of type 2 diabetes using a targeted metabolomic approach. Diabetes 2013; 62(2): 639-48.

8. Qiu G, Zheng Y, Wang H, et al. Plasma metabolomics identified novel metabolites associated with risk of type 2 diabetes in two prospective cohorts of Chinese adults. Int J Epidemiol 2016; 45(5): 1507-16.

9. Wang TJ, Larson MG, Vasan RS, et al. Metabolite profiles and the risk of developing diabetes. Nat Med 2011; 17(4): 448-53.

10. Wang-Sattler R, Yu Z, Herder C, et al. Novel biomarkers for pre-diabetes identified by metabolomics. Mol Syst Biol 2012; 8: 615.

11. Ferrannini E, Natali A, Camastra S, et al. Early metabolic markers of the development of dysglycemia and type 2 diabetes and their physiological significance. Diabetes 2013; 62(5): 1730-7. 
medRxiv preprint doi: https://doi.org/10.1101/2021.10.11.21264833; this version posted October 14,2021 . The copyright holder for this preprint (which was not certified by peer review) is the author/funder, who has granted medRxiv a license to display the preprint in

All rights reserved. No reuse allowed without permission.

12. Tillin $T$, Hughes AD, Wang $Q$, et al. Diabetes risk and amino acid profiles: cross-sectional and prospective analyses of ethnicity, amino acids and diabetes in a South Asian and European cohort from the SABRE (Southall And Brent REvisited) Study. Diabetologia 2015; 58(5): 968-79.

13. Zhao J, Zhu Y, Hyun N, et al. Novel metabolic markers for the risk of diabetes development in American Indians. Diabetes Care 2015; 38(2): 220-7.

14. Peddinti G, Cobb J, Yengo L, et al. Early metabolic markers identify potential targets for the prevention of type 2 diabetes. Diabetologia 2017; 60(9): 174050.

15. Sudlow C, Gallacher J, Allen N, et al. UK Biobank: An Open Access Resource for Identifying the Causes of a Wide Range of Complex Diseases of Middle and Old Age. PLOS Medicine 2015; 12(3): e1001779.

16. Allen N, Arnold M, Parish S, et al. Approaches to minimising the epidemiological impact of sources of systematic and random variation that may affect biochemistry assay data in UK Biobank Wellcome Open Research 2021; 5: 222.

17. Littlejohns TJ, Holliday J, Gibson LM, et al. The UK Biobank imaging enhancement of 100,000 participants: rationale, data collection, management and future directions. Nat Commun 2020; 11(1): 2624.

18. UK Biobank. Repeat Assessment Data, Version 1.0: UK Biobank, 2013.

19. Würtz P, Kangas AJ, Soininen P, Lawlor DA, Davey Smith G, Ala-Korpela M. Quantitative Serum Nuclear Magnetic Resonance Metabolomics in LargeScale Epidemiology: A Primer on -Omic Technologies. Am J Epidemiol 2017; 186(9): 1084-96.

20. Soininen $P$, Kangas AJ, Würtz P, Suna T, Ala-Korpela M. Quantitative serum nuclear magnetic resonance metabolomics in cardiovascular epidemiology and genetics. Circ Cardiovasc Genet 2015; 8(1): 192-206.

21. Julkunen $H$, Cichońska $A$, Slagboom PE, Würtz $P$, Nightingale Health UKBI. Metabolic biomarker profiling for identification of susceptibility to severe pneumonia and COVID-19 in the general population. eLife 2021; 10: e63033.

22. Benjamini Y, Hochberg Y. Controlling the False Discovery Rate: A Practical and Powerful Approach to Multiple Testing. Journal of the Royal Statistical Society: Series B (Methodological) 1995; 57(1): 289-300.

23. Wilson PW, Meigs JB, Sullivan L, Fox CS, Nathan DM, D'Agostino RB, Sr. Prediction of incident diabetes mellitus in middle-aged adults: the Framingham Offspring Study. Arch Intern Med 2007; 167(10): 1068-74. 
medRxiv preprint doi: https://doi.org/10.1101/2021.10.11.21264833; this version posted October 14, 2021. The copyright holder for this preprint (which was not certified by peer review) is the author/funder, who has granted medRxiv a license to display the preprint in All rights reserved. No reuse allowed without permission.

24. Harrell FE, Jr., Lee KL, Mark DB. Multivariable prognostic models: issues in developing models, evaluating assumptions and adequacy, and measuring and reducing errors. Stat Med 1996; 15(4): 361-87.

25. Pencina MJ, D'Agostino RB, Sr, D'Agostino RB, Jr, Vasan RS. Evaluating the added predictive ability of a new marker: From area under the ROC curve to reclassification and beyond. Stat Med 2008; 27(2): 157-72.

26. Pencina MJ, D'Agostino RB, Sr, Steyerberg EW. Extensions of net reclassification improvement calculations to measure usefulness of new biomarkers. Stat Med 2011; 30(1): 11-21.

27. Ahola-Olli AV, Mustelin L, Kalimeri M, et al. Circulating metabolites and the risk of type 2 diabetes: a prospective study of 11,896 young adults from four Finnish cohorts. Diabetologia 2019; 62(12): 2298-309.

28. Mackey RH, Mora S, Bertoni AG, et al. Lipoprotein Particles and Incident Type 2 Diabetes in the Multi-Ethnic Study of Atherosclerosis. Diabetes Care 2015; 38(4): 628-36.

29. Garvey WT, Kwon S, Zheng D, et al. Effects of insulin resistance and type 2 diabetes on lipoprotein subclass particle size and concentration determined by nuclear magnetic resonance. Diabetes 2003; 52(2): 453-62.

30. Mahendran Y, Jonsson A, Have CT, et al. Genetic evidence of a causal effect of insulin resistance on branched-chain amino acid levels. Diabetologia 2017; 60(5): 873-8.

31. Lotta LA, Scott RA, Sharp SJ, et al. Genetic Predisposition to an Impaired Metabolism of the Branched-Chain Amino Acids and Risk of Type 2 Diabetes: A Mendelian Randomisation Analysis. PLoS Med 2016; 13(11): e1002179.

32. Qian F, Ardisson Korat AV, Imamura F, et al. n-3 Fatty Acid Biomarkers and Incident Type 2 Diabetes: An Individual Participant-Level Pooling Project of 20 Prospective Cohort Studies. Diabetes Care 2021; 44: 1133-42.

33. Pearson E, Adamski J. The search for predictive metabolic biomarkers for incident T2DM. Nat Rev Endocrinol 2018; 14(8): 444-6.

34. Fall T, Salihovic S, Brandmaier S, et al. Non-targeted metabolomics combined with genetic analyses identifies bile acid synthesis and phospholipid metabolism as being associated with incident type 2 diabetes. Diabetologia 2016; 59(10): 2114-24.

35. Herder C, Kowall B, Tabak AG, Rathmann W. The potential of novel biomarkers to improve risk prediction of type 2 diabetes. Diabetologia 2014; 57(1): 16-29. 
medRxiv preprint doi: https://doi.org/10.1101/2021.10.11.21264833; this version posted October $14,2021$. The copyright holder for this preprint (which was not certified by peer review) is the author/funder, who has granted medRxiv a license to display the preprint in

All rights reserved. No reuse allowed without permission.

36. Tikkanen E, Jägerroos V, Rodosthenous R, et al. Metabolic Biomarkers for Peripheral Artery Disease Compared with Coronary Artery Disease:

Lipoprotein and metabolite profiling of 31,657 individuals from five prospective cohorts. medRxiv 2020: 2020.07.24.20158675.

37. Li-Gao R, Hughes DA, le Cessie S, et al. Assessment of reproducibility and biological variability of fasting and postprandial plasma metabolite concentrations using 1H NMR spectroscopy. PLOS ONE 2019; 14(6): e0218549.

38. Fry A, Littlejohns TJ, Sudlow C, et al. Comparison of Sociodemographic and Health-Related Characteristics of UK Biobank Participants With Those of the General Population. Am J Epidemiol 2017; 186(9): 1026-34. 
medRxiv preprint doi: https://doi.org/10.1101/2021.10.11.21264833; this version posted October 14, 2021. The copyright holder for this preprint (which was not certified by peer review) is the author/funder, who has granted medRxiv a license to display the preprint in

All rights reserved. No reuse allowed without permission.

\section{Figure legends}

Figure 1. Associations of metabolic biomarkers with risk of incident type 2 diabetes

Hazard ratios (with 95\% confidence intervals) are presented per 1-SD higher metabolic biomarker on the natural log scale, stratified by age-at-risk and sex and adjusted for assessment centre, Townsend deprivation index, smoking, drinking, body mass index, waist-to-hip ratio, fasting duration and spectrometer. *false discovery rate controlled $p<0.05$.

Apo-A1=apolipoprotein A1; Apo-B=apolipoprotein B; DHA=docosahexaenoic acid; $F A=$ fatty acids; $F A w 3=$ omega -3 fatty acids; $F A w 6=0$ mega -6 fatty acids; $H D L=$ high density lipoproteins; HDL-D=high density lipoprotein particle diameter; $\mathrm{IDL}=$ intermediate density lipoproteins; $\mathrm{L}=\operatorname{large}$; $\mathrm{LA}=$ linoleic acid; $\mathrm{LDL}=$ low density lipoproteins; LDL-D=low density lipoprotein particle diameter; LP=lipoprotein; $\mathrm{M}=$ medium; MUFA=monounsaturated fatty acids; PUFA=polyunsaturated fatty acids; $\mathrm{S}=$ small; SFA=saturated fatty acids; T2D=type 2 diabetes; VLDL=very low density lipoproteins; VLDL-D=very low density lipoprotein particle diameter; $X L=$ very large; $\mathrm{XS}=$ very small; $\mathrm{XXL}=$ extremely large.

\section{Figure 2. Calibration of prediction models for incident type 2 diabetes from cross-validation}

For each model, the observed and predicted T2D event rates are shown for each of 10 equally-sized groups of absolute predicted risk. Vertical lines represent $95 \% \mathrm{Cls.}$ Calibration slopes are presented from 10-fold cross-validation (pooled using inverse variance weighting) and were derived from a Cox regression of the predicted risk on the observed risk. Basic model: age, sex, parental history of diabetes, body mass index, $\mathrm{HbA1c}$. Extended model: basic model plus waist circumference, triglycerides, and HDL-cholesterol. Metabolic biomarkers comprise the first 11 metabolic biomarker principal components. 
medRxiv preprint doi: https://doi.org/10.1101/2021.10.11.21264833; this version posted October 14,2021 . The copyright holder for this preprint (which was not certified by peer review) is the author/funder, who has granted medRxiv a license to display the preprint in

All rights reserved. No reuse allowed without permission.

Table 1. Baseline characteristics by incident type 2 diabetes status

\begin{tabular}{|c|c|c|c|}
\hline \multirow{2}{*}{ Baseline characteristics ${ }^{\star}$} & \multicolumn{2}{|c|}{ Incident type 2 diabetes } & \multirow{2}{*}{ Total } \\
\hline & Yes & No & \\
\hline $\begin{array}{l}\text { No. of participants } \\
\text { Age, sex and socioeconomic factors }\end{array}$ & 1719 & 63965 & 65684 \\
\hline Mean age (SD), years & $57.1(7.7)$ & $55.1(8.0)$ & $55.2(8.0)$ \\
\hline Women, \% & 47 & 58 & 58 \\
\hline Townsend Deprivation Index (SD) $^{\dagger}$ & $0.3(1.1)$ & $0.0(1.0)$ & $0.0(1.0)$ \\
\hline \multicolumn{4}{|l|}{ Lifestyle factors } \\
\hline \multicolumn{4}{|l|}{ Smoking, \% } \\
\hline Never or occasional & 54 & 61 & 61 \\
\hline Previous & 33 & 32 & 32 \\
\hline Current regular & 14 & 7 & 7 \\
\hline \multicolumn{4}{|l|}{ Alcohol drinking, \% } \\
\hline Never or occasional & 42 & 25 & 26 \\
\hline Previous & 5 & 3 & 3 \\
\hline Current regular & 53 & 71 & 71 \\
\hline \multicolumn{4}{|l|}{ Anthropometry, mean (SD) } \\
\hline $\mathrm{BMI}, \mathrm{kg} / \mathrm{m}^{2}$ & $31.5(5.2)$ & $26.8(4.5)$ & $26.9(4.4)$ \\
\hline WC, cm & $100(13)$ & $88(12)$ & $88(13)$ \\
\hline $\mathrm{HC}, \mathrm{cm}$ & $110(10)$ & $103(9)$ & $103(9)$ \\
\hline WHR & $0.91(0.08)$ & $0.86(0.09)$ & $0.86(0.09)$ \\
\hline Parental history of diabetes, \% & 38 & 18 & 19 \\
\hline Mean HbA1c (SD), \% & $5.8(0.4)$ & $5.3(0.3)$ & $5.3(0.3)$ \\
\hline Mean fasting time (SD), hours & $4.0(2.6)$ & $3.7(2.4)$ & $3.7(2.4)$ \\
\hline
\end{tabular}

${ }^{*}$ Standardised to age and sex structure of the study population

†Standardised Townsend Deprivation Index, higher scores represent higher levels of deprivation

$\mathrm{BMI}=$ body mass index; $\mathrm{HC}=$ hip circumference; WC=waist circumference; WHR=waist-to-hip ratio 
medRxiv preprint doi: https://doi.org/10.1101/2021.10.11.21264833; this version posted October 14, 2021. The copyright holder for this preprint (which was not certified by peer review) is the author/funder, who has granted medRxiv a license to display the preprint in perpetuity.

All rights reserved. No reuse allowed without permission.

Table 2. Performance of risk prediction models for incident type 2 diabetes

\begin{tabular}{|c|c|c|c|c|}
\hline Performance metric & Basic model* & $\begin{array}{c}\text { Basic model* plus } \\
\text { metabolic } \\
\text { biomarkers } \dagger\end{array}$ & Extended model $¥$ & $\begin{array}{c}\text { Extended model } ¥ \\
\text { plus metabolic } \\
\text { biomarkers } \dagger\end{array}$ \\
\hline C-statistic (Cl) § & $0.802(0.791,0.812)$ & $0.830(0.822,0.841)$ & $0.829(0.819,0.838)$ & $0.837(0.831,0.848)$ \\
\hline \multicolumn{5}{|c|}{ Metrics of relative performance } \\
\hline$\chi^{2} \| \#$ & \multicolumn{2}{|c|}{$453(p<0.0001)$} & \multicolumn{2}{|c|}{$177(p<0.0001)$} \\
\hline$\%$ increase $\chi^{2}$ & \multicolumn{2}{|c|}{17} & \multicolumn{2}{|c|}{6} \\
\hline Absolute IDI \# \$ & \multicolumn{2}{|c|}{$1.5(1.0,1.9)$} & \multicolumn{2}{|c|}{$0.7(0.4,1.1)$} \\
\hline Relative IDI (\%) (Cl) \# \$ & \multicolumn{2}{|c|}{$15.0(10.5,20.4)$} & \multicolumn{2}{|c|}{$6.3(4.1,9.8)$} \\
\hline \multicolumn{5}{|l|}{ Continuous NRI (Cl) \# ** } \\
\hline Events & \multicolumn{2}{|c|}{$0.15(0.12,0.20)$} & \multicolumn{2}{|c|}{$0.10(0.06,0.14)$} \\
\hline Non-events & \multicolumn{2}{|c|}{$0.28(0.26,0.31)$} & \multicolumn{2}{|c|}{$0.12(0.09,0.14)$} \\
\hline Overall & \multicolumn{2}{|c|}{$0.44(0.38,0.49)$} & \multicolumn{2}{|c|}{$0.22(0.17,0.28)$} \\
\hline
\end{tabular}

${ }^{*}$ Basic model: age, sex, parental history of diabetes, body mass index, $\mathrm{HbA1c}$

† Metabolic biomarkers comprise the first 11 metabolic biomarker principal components

‡ Extended model: basic model plus waist circumference, blood pressure, triglycerides, HDL-cholesterol

$\S$ The c-statistic measures the ability of a model to rank participants from low to high risk. Given two randomly selected individuals, one who develops T2D and one who does not, the c-statistic is the probability that the model will give a higher predicted risk for the individual who develops T2D. An uninformative model will have a c-statistic of 0.5 and a model that discriminates perfectly will have a c-statistic of 1.0 .

$\| 11 \mathrm{DF}$

\# Bias-corrected estimates and confidence intervals were derived using 200 bootstrap samples

\$ The IDI quantifies the difference between two models in their ability to predict risk. It is calculated as the difference between the two models in the mean predicted T2D risk among those who did develop T2D minus the mean predicted risk of T2D in those who did not develop T2D (i.e., it is the difference between two differences). When metabolic biomarkers were added to the basic model, the separation in mean predicted T2D risk between those who did develop T2D, compared with those who did not develop T2D, increased in relative terms by $15.0 \%$. Positive IDI values indicate improved T2D risk classification following addition of metabolic biomarkers to the risk prediction model.

** The continuous NRI quantifies the appropriateness of the change in predicted probabilities of T2D between two models. The 'Events' NRI is calculated among those who developed T2D, and the 'Non-events' NRI is calculated among those who did not develop T2D. Both statistics are calculated as the probability of an 'appropriate' change in predicted risk (after addition of metabolic biomarkers to the model) minus the probability of an 'inappropriate' change in predicted risk. For those who developed T2D, an appropriate change would b e a higher predicted T2D risk after addition of metabolic biomarkers to the model. An inappropriate change would be a lower predicted T2 $\mathrm{D}$ risk after addition of metabolic biomarkers to the model. When metabolic biomarkers were added to the basic model, among those who developed T2D, 15\% more were assigned a higher predicted T2D risk than were assigned a lower predicted risk. The overall NRI is the $s$ um of the 'Events' and 'Non-events' NRI statistics. Positive NRI values indicate that addition of metabolic biomarkers results in a superior model.

$\mathrm{DF}=$ degrees of freedom; $|\mathrm{DI}|=$ integrated discrimination improvement; $N R I=$ net reclassification improvement; $T 2 \mathrm{D}=$ type 2 diabetes 
Figure 1. Associations of metabolic biomarkers with risk of incident type 2 diabetes

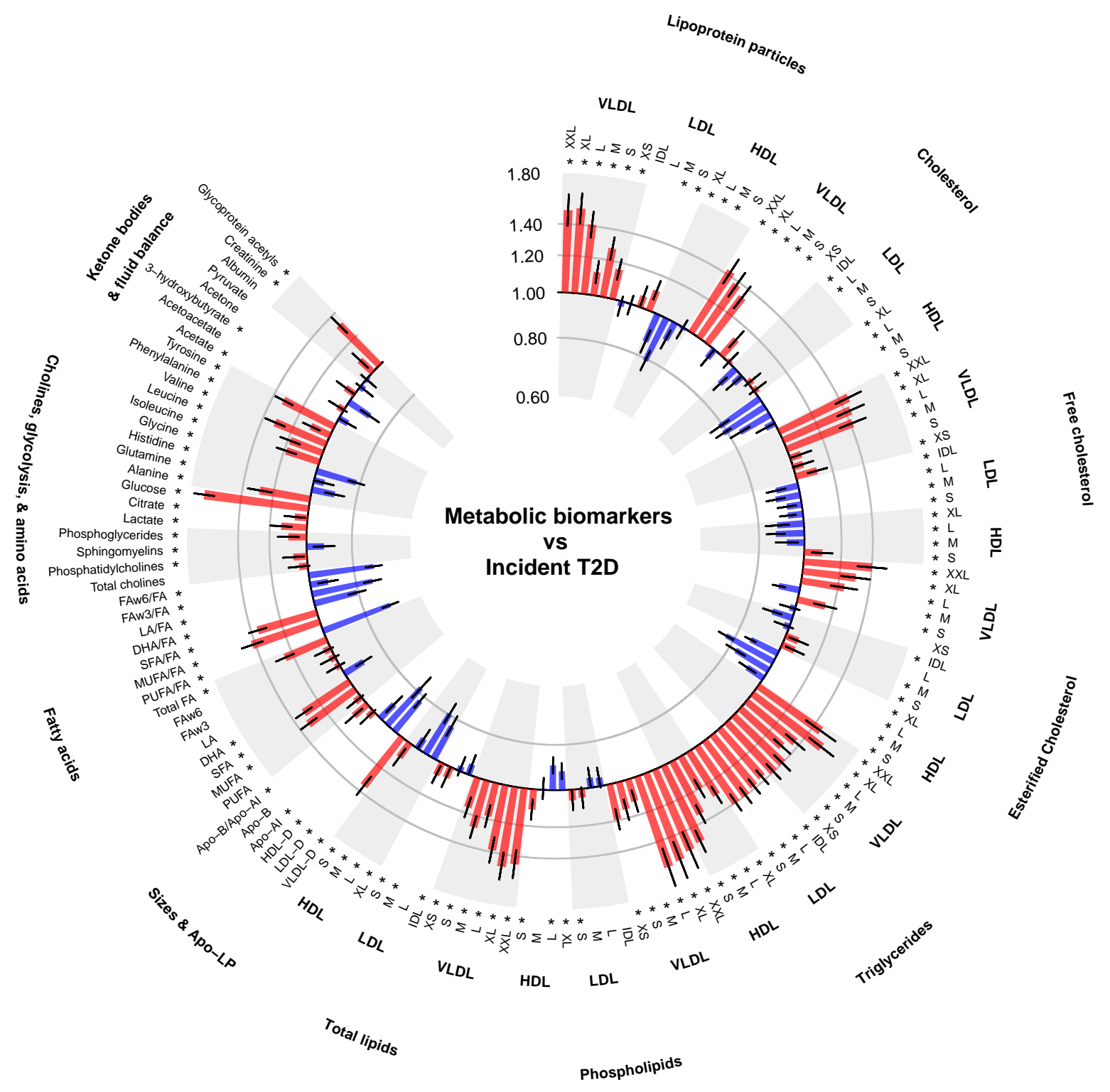


medRxiv preprint doi: https://doi.org/10.1101/2021.10.11.21264833; this version posted October 14,2021 . The copyright holder for this preprint (which was not certified by peer review) is the author/funder, who has granted medRxiv a license to display the preprint in

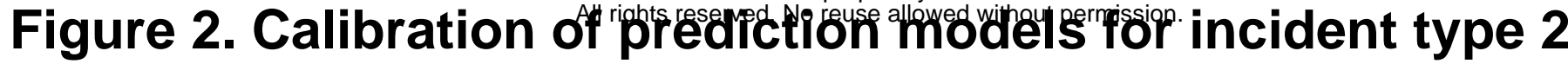 diabetes from cross-validation}

\section{Basic model}

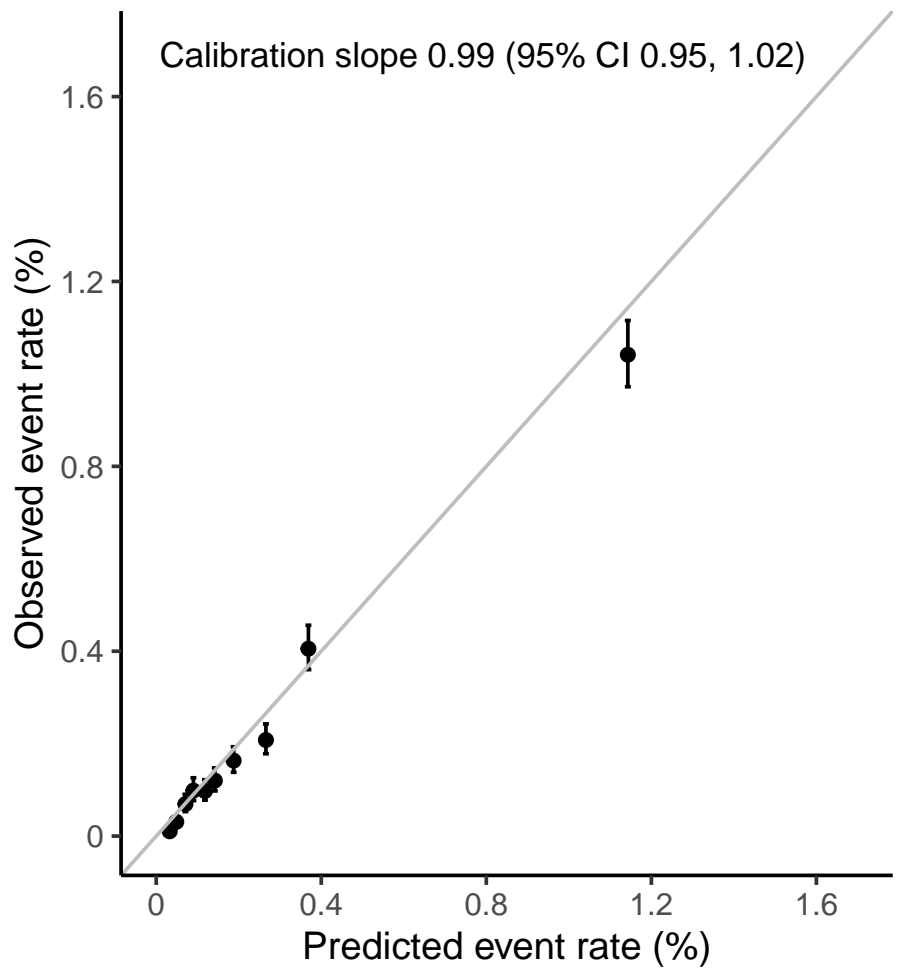

Extended model

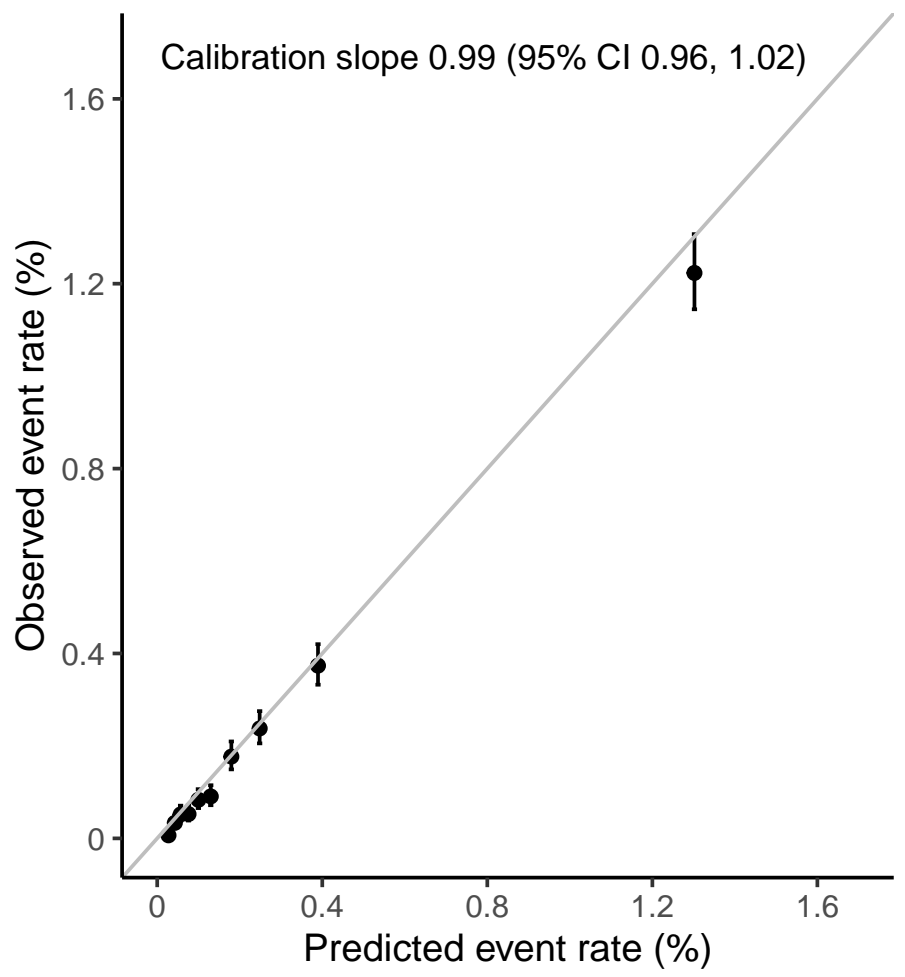

Basic model + metabolic biomarkers

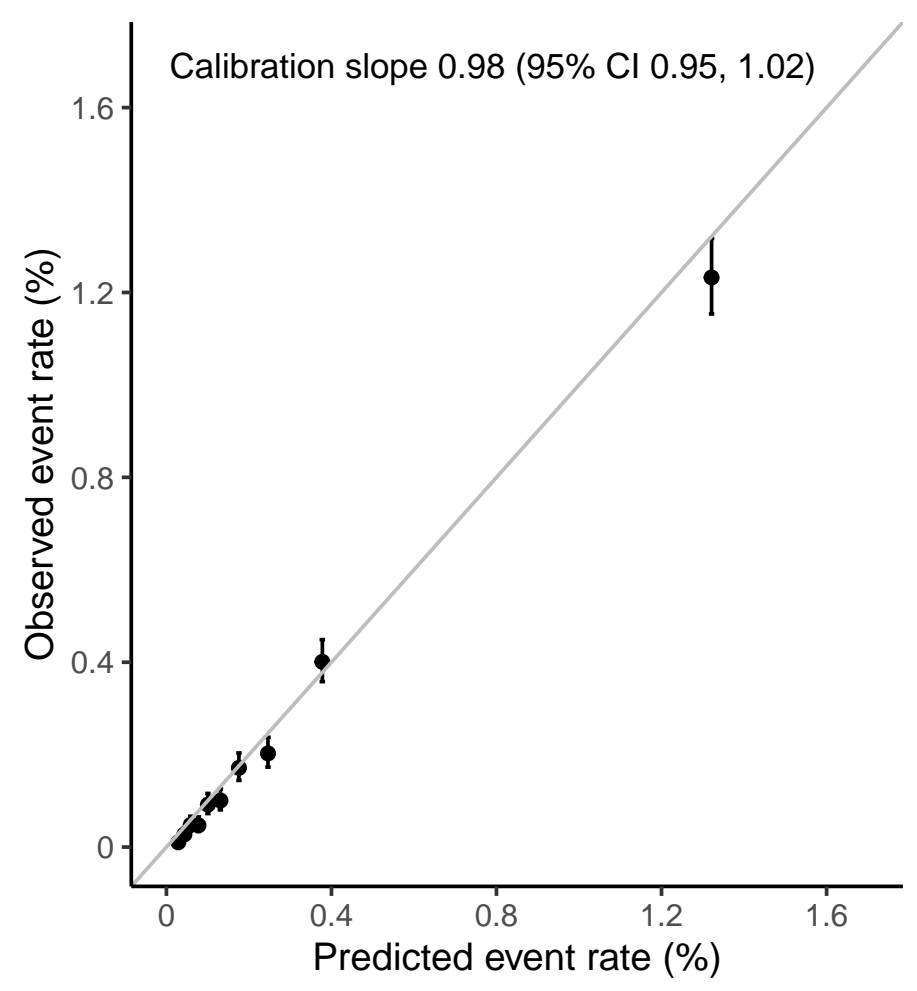

Extended model + metabolic biomarkers

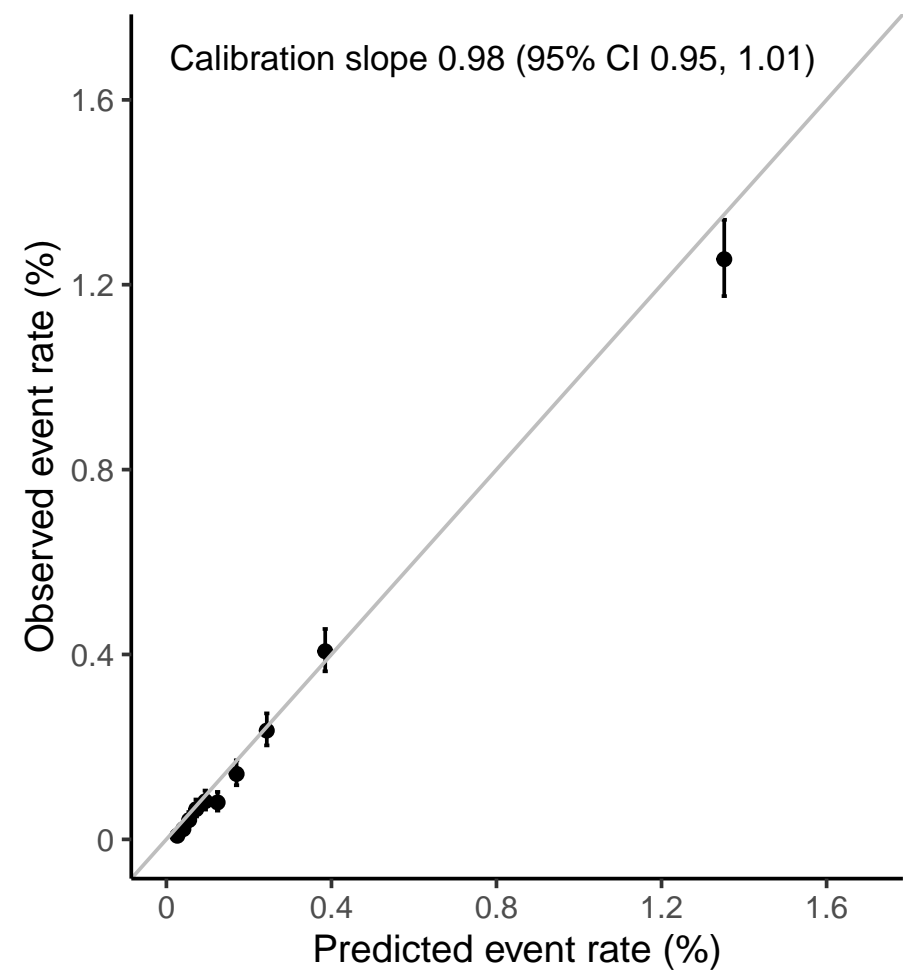

